\title{
Variations in chemical composition, antimicrobial and haemolytic activities of peel essential oils from three local Citrus cultivars
}

\author{
Rahman Qadir ${ }^{1}$, Farooq Anwar ${ }^{*}$, Tahir Mehmood ${ }^{1}$, Muhammad \\ Shahid ${ }^{2}$ and Sadaf Zahoor ${ }^{1}$ \\ 1. Department of Chemistry, University of Sargodha, Sargodha-40100-Pakistan \\ 2. Department of Biochemistry, University of Agriculture Faisalabad-38040-Pakistan \\ *Corresponding author's email: fqanwar@yahoo.com \\ Citation
}

Rahman Qadir, Farooq Anwar, Tahir Mehmood, Muhammad Shahid and Sadaf Zahoor. Variations in chemical composition, antimicrobial and haemolytic activities of peel essential oils from three local Citrus cultivars. Pure and Applied Biology. Vol. 7, Issue 1, pp282-291. http://dx.doi.org/10.19045/bspab.2018.70034

\begin{tabular}{llll}
\hline \hline Received: 11/01/2018 & Revised: 13/02/2018 & Accepted: 15/02/2018 & Online First: 16/02/2018 \\
\hline \hline
\end{tabular}

\section{Abstract}

The present research work was carried out to appraise the variations in the chemical composition, antimicrobial and haemolytic activities of hydro-distilled essential oils from peels of three Citrus cultivars including Citrus reticulata (Kinnow), Citrus sinensis (Mussammi), and Citrus $x$ sinensis (Red blood orange). The essential oil yield from the peels of these cultivars was found to be $0.86,1.70$ and $1.07 \%$, respectively. Overall, the major chemical constituents (GC-FID analysis) in the peel essential oils of $C$. reticulata, $C$. sinensis and $C . x$ sinensis were identified to be limonene (46.30-54.57\%), geraniol (10.02-24.00\%) and citraniol (10.05-14.00\%). Among the oils tested, peel essential oil of $C$. reticulata exhibited maximum zone of inhibition against bacterial strains whereas that of $C . x$ sinensis against fungal strains. The tested peel essential oils exhibited small extent of haemolytic activity $(0.29$ to $1.09 \%)$ indicating negligible cytotoxicity. The antibacterial, antifungal and haemolytic activities of the tested Citrus peel essential oils varied considerably $(p<0.05)$ among cultivars depending upon the variable composition of the oils.

Keywords: Antimicrobial agents; Cell; Citrus Peel essential oil; GC-FID; Hydrodistillation

\section{Introduction}

Essential oils are odorous volatile components isolated from different parts of aromatic plants [1, 2]. Plant essential oils are often employed to impart flavor to drinks and foods as well as are used as ingredients in the formulations of pharmaceuticals, perfumes and cosmetics products [3]. Besides multiple industrial applications, the essential oils are recently gaining greater recognition due to their potential biological such as antioxidant, antimicrobial and bio-pesticidal properties $[4,5]$.

The genus Citrus, from Rutaceae family, comprises 1,300 species and 140 genera. $C$. sinensis (Orange), C. paradise (Grapefruit), $C$. reticulata (Tangerine), $C$. grandis (Shaddock), $C$. limon (Lemon), $C$. aurantium (Sour orange) and C. medica (Citron) are some of the important fruit species of genus Citrus. Citrus are grown for their fruits in several countries with tropical climates such as Egypt, Pakistan, 
China, Brazil, The United States, Turkey, India, Nigeria and Spain [6].

Citrus fruits are valuable food commodity which is popular across the world due to high nutritional value and medicinal benefits. Several in-vitro and in-vivo studies have indicated Citrus fruits to be useful against chronic diseases such as cancers and cardiovascular diseases due to the presence of high amount of vitamin $\mathrm{C}$ and phenolic bioactives with antioxidant potential [7].

As results of large scale Citrus fruit consumption, huge amount of peels are generated annually, which are often discarded as agro-waste instead of revalorized into value-added products. According to estimates, processing of Citrus fruit generates peels and membrane residues containing about $40-45 \%$ of fruit mass as a waste fraction [8]. Interestingly, Citrus peels can be explored as a valuable source of essential oil [9]. Citrus peel essential oils have been investigated for their potential biological roles such as antioxidant, antimicrobial and antiinflammatory properties [10]. The volatile chemical compounds such as $\alpha$-terpineol, linalool and $\alpha$-pinene, present in Citrus peel essential oils, can be linked to antifungal and antibacterial activities [11]. Recently, due to growing microbial drug resistance there is increasing interest in the investigation of essential oils as natural antimicrobial agents $[4,5]$. Nevertheless, the oil yield and biochemical composition of plant essentials oils not only vary within the species and its varieties but also among different agro-climatic and geographical regions $[4,5]$. Various studies reveal the chemical composition and potential biological activities of Citrus peel essential oils $[3,6,8,9]$, however rarely data is available on the inter-cultivar variations in the volatiles composition and biological properties of Citrus peel essential oils. This prompts the need to appraise the variations in the chemicals profile and biological attributes of peel essential oils from different local cultivars of Citrus.
In perspectives of value-addition, currently, there is increasing interest on the exploration of under-utilized fruit processing agro-wastes (such as peels) for isolation of high-value bioactives and volatile oils $[12,13]$. In Pakistan, consumption of Citrus is made on large scale both in terms of whole fruit intake and fruit processing by-products. As results of wide scale Citrus fruit consumption, a substantial quantity of Citrus peels is produced annually that can be utilized for production of essential oil. Rarely efforts have been made towards studying the comprehensive compositional analysis and biological principles of peel essential oils of different Citrus cultivars in Pakistan. In the present research variations in the yield, chemical composition and biological activities (antifungal, antibacterial and haemolytic activities) of peel essential oils from three widely cultivated and consumed Citrus cultivars (Citrus reticulata, Citrus sinensis, Citrus $\times$ sinensis) were appraised.

\section{Materials and methods \\ Collection of samples}

Fresh fruits of three Citrus cultivars such as Kinnow ( $C$. reticulata), Musammi ( $C$. sinensis) and Red blood orange (C. $\times$ sinensis) were collected through local market of Sargodha, Pakistan. The fruits were peeled off using a sharp steel knife. Small pieces were made from recovered peels with a knife and dried under shade in a laboratory. The shade-dried peel material was crushed using a domestic grinder and packed in polyethylene zipped bags.

\section{Isolation of the essential oil}

The essential oil was isolated via Clevenger- type apparatus using hydrodistillation technique [14]. The ground Citrus peels material was hydro-distilled for $3 \mathrm{~h}$. Distillates of the essential oil were collected and dehydrated over anhydrous sodium sulphate $\left(\mathrm{Na}_{2} \mathrm{SO}_{4}\right)$, filtered and then kept at fridge temperature $\left(4^{\circ} \mathrm{C}\right)$ until analysed [15].

\section{Chemical analysis of the essential oil}

Analysis of Citrus peel essential oils was carried out using a Gas Chromatographic 
system (Schimadzu) attached to an FID (flame ionization detector). Compounds were separated on DB-5 capillary column. Nitrogen (mobile phase) was flushed at a flow rate of $5 \mathrm{~mL} / \mathrm{min}$. Initial column temperature was held at $80{ }^{\circ} \mathrm{C}$ for $2 \mathrm{~min}$ and auto increased to $240{ }^{\circ} \mathrm{C}$ at the rate of $10{ }^{\circ} \mathrm{C}$ /min. The percent composition of the compounds was reported relative to total peak areas.

\section{Antimicrobial activity Microbial strains}

Two Gram-positive bacteria such as $S$. aureus (Staphylococcus aureus) API Staph TAC 6736152, and B. subtilis (Bacillus subtilis) JS 2004 and two Gram-negative bacteria such as E. coli (Escherichia coli) ATCC 25922, and P. multocida (Pasteurella multocida) (local isolate) were employed to test the isolated essential oils. Four pathogenic forms of fungi including C. albican (Candida albicans), M. canis (Microsporum canis), A. flavus (Aspergillus flavus) and F.solani (Fusarium solani) were used to test the antifungal potential of the essential oils. The above mentioned pure microbial strains were acquired from the Clinical Medicine and Surgery Department, University of Agriculture, Faisalabad, Pakistan. Purity and identity were verified and authenticated by the Department of Microbiology at University of Agriculture, Faisalabad, Pakistan. The bacterial strains were cultured in Nutrient agar (NA, Oxoid) overnight at $37{ }^{\circ} \mathrm{C}$ while fungal strains were cultured in Potato dextrose agar (PDA, Oxoid) overnight at $28^{\circ} \mathrm{C}$.

\section{Disc diffusion method}

The antimicrobial activity of the essential oils was evaluated by disc diffusion method $[4,5]$. Briefly, a $100 \mu \mathrm{L}$ tested microorganism's suspension, having $10^{7}$ colony-forming units $(\mathrm{CFU}) / \mathrm{mL}$ of bacteria and $10^{6}$ spores/mL of fungi, were spread on NA and PDA medium, respectively. The compound's solution was added in filter discs (6 $\mathrm{mm}$ in diameter) and employed on the agar plates which had formerly been inoculated with the tested microorganisms.
Sample-less discs were employed as a negative control. For bacteria and fungi, Amoxycillin (30 $\mu \mathrm{g} / \mathrm{dish})$ (Oxoid, UK) and Flumequine $(30 \mu \mathrm{g} / \mathrm{disk}$ ] (Oxoid, UK) were set as positive reference to compare sensitivities of strain/isolate. After placing for $2 \mathrm{~h}$ at $4^{\circ} \mathrm{C}$, plates were incubated at $37^{\circ} \mathrm{C}$ for about $18 \mathrm{~h}$ for bacteria and at $28^{\circ} \mathrm{C}$ for $24 \mathrm{~h}$ for fungal strains. By calculating the diameters of the growth inhibition zones (zone reader) of the organisms, antimicrobial activity was evaluated and compared with the controls $[16,17]$.

\section{Haemolytic activity}

Haemolytic activity of the tested essential oils was evaluated by a prescribed procedure. [18, 19]. Freshly heparinized human blood $(3 \mathrm{~mL})$ was taken from healthy volunteers. The bold was centrifuged for 5 min at $1000 \mathrm{x} g$; plasma was poured off and cells were washed three times with $5 \mathrm{~mL}$ of chilled $\left(4^{\circ} \mathrm{C}\right)$ sterile isotonicphosphatebuffered saline (PBS) of pH7.4. In each assay,erythrocytes were preserved at $10^{8}$ cells per $\mathrm{mL}$. Each cultivar's essential oil $(100 \mu \mathrm{L})$ was taken and agitated with RBC $\left(10^{8}\right.$ cells $\left./ \mathrm{mL}\right)$ independently. Incubation of samples was done for $35 \mathrm{~min}$ at $37^{\circ} \mathrm{C}$. Instantaneously, after incubating, the samples were kept in ice for $5 \mathrm{~min}$ and then centrifuged for $5 \mathrm{~min}$ at $1000 \times \mathrm{g}$. A $100-\mu \mathrm{L}$ supernatant was collected from each tube and diluted 10 time with chilled $\left(4^{\circ} \mathrm{C}\right) \mathrm{PBS}$. The positive and negative controls employed were Triton X-100 and phosphate buffer saline (PBS), respectively. Using $\mu$ Quant (Bioteck, USA) the absorbance was observed at $576 \mathrm{~nm}$ and \% RBCs lysis for each sample was computed.

\section{Results and discussion}

\section{Peel portion and essential oils yield}

The results regarding \% peel portion and \% oil yield of essential oils obtained for three cultivars of Citrus including Citrus reticulata (Musammi), Citrus sinensis (Kinnow), Citrus $x$ sinensis (Red blood orange orange) are presented in (Table 1). The content of $\%$ peel portion from fruits of Red blood orange was higher $(36.0 \%)$ 
followed by Musammi (34.50\%) and then Kinnow (31.67\%). These outcomes are in accordance with the findings of other scientists. Weiss [20], observed that peel portions of mandarin, sweet orange and lemon were 28.0, 25.0 and $40.0 \%$, respectively. In another work of Manthey \& Grohmann [21], peel portions from citrus fruits such as orange, grape fruit and lemon generated 25.6 - 33.0, 21.5 - 38.1, 33.7 36.4 and 32.0 - $46.6 \%$ of peel mass, respectively. Such variations in the peel mass of selected species from Sargodha region can be attributed to changing environmental factors of area as well as the genotype. These variable morphological and genetical traits of fruits play effective role in altering the composition of peels [22].

Among the Citrus species, extracted through Clevenger apparatus using hydrodistillation method, Musammi $(C$. sinensis) peels exhibited maximum oil yield $(1.76 \%)$ followed by Red blood orange $(C$. $\mathrm{x}$ sinensis $)(1.06 \%)$ and Kinnow $(C$. reticulata) $(0.86 \%)$. The results obtained were compatible with the findings of Weiss [20] who reported the peel essential oil yield from sweet orange, lemon as well as mandarin to be $0.80,0.90$ and $0.80 \%$ respectively, while bergamot orange had $0.45-0.65 \%$ peel oil yield. Notable variations in the oil yield from different Citrus cultivars can be mainly linked to the fruit genotype. In another study, cold pressed peel oil yield from oranges, and bergamot petitgrain was $0.5 \%$ each whereas, mandarin oil had $0.2 \%$ yield, Anon [23]. According to Ahmad et al. [24], the highest oil yield (1.21\%) was obtained from Malta peel followed by Eureka,s lemon (1.12\%), Musammi (0.98\%) and Grapefruit (0.73\%). Kamal et al. [25], reported that highest oil yield was exhibited by $C$. sinensis $(0.23-1.08 \%)$, followed by $C$. reticulata $(0.31-0.52 \%)$ and then $C$. paradise (0.21-0.43\%). Tue et al. [26] reported that yield of peel essential oils differed from 0.2-2.0\% among different citrus species.

Table 1. Peel portion and yield of peel essential oil from different Citrus cultivars

\begin{tabular}{|l|l|l|}
\hline Cultivar Common Name & \% Peel portion & \% Oil yield \\
\hline Citrus sinensis (Musammi) & $34.50 \pm 0.50$ & $1.76 \pm 0.10$ \\
\hline Citrus $x$ sinensis (Red blood orange) & $36.00 \pm 1.00$ & $1.06 \pm 0.10$ \\
\hline Citrus reticulata (Kinnow) & $31.67 \pm 1.15$ & $0.86 \pm 0.05$ \\
\hline
\end{tabular}

The data are mean \pm S.D. of peel essential oil from three different samples of each Citrus cultivar analysed in triplicate

\section{Chemical composition of citrus peel essential oils}

The percent composition of major chemical components identified in the essential oils from peels of three different Citrus cultivars is depicted in (Table 2). The data, derived from GC-FID analysis, revealed a significant qualitative and quantitative variation in the chemical profile of the oils from selected Citrus cultivars. Based upon matching the relative retention time with those of pure standards, major chemical constituents $(>1 \%)$ detected in essential oils of peels from $C$. reticulata, $C$. sinensis and
C. $x$ sinensis were limonene, linalool and citranellal, respectively. Nerol, eugenol, geraniol and ethyl benzoate $\beta$-myrcene, and linalool oxide were also present in considerable amounts.

The present study values are in close agreement with the results of Geraci et al. [27] who described that the key components of these oils were myrcene, limonene,nerol, $\beta$-pinene and geraniol, . Lota et al. [28] reported two major monoterpenes: limonene and $\gamma$-terpinene in essential oils from peels of Citrus reticulata [mandarin]. According to Feger et al. [29], the chief component in peel oils of 
Brazillian Murcot Tangerines was noted to be limonene.

A comparative study, reported on the chemical composition of peel essential oils isolated from Italian Sweet lime as well as Bergamot, revealed that both the oils have quite comparable chemical composition $[30,31]$. The differences in the composition of citrus peel oils from different cultivars and regions can be attributed to the agroclimatic and genetic factors $[32,33]$

Table 2. GC-FID percent chemical composition of peel essential oil from different Citrus cultivars

\begin{tabular}{|l|l|l|c|c|}
\hline Volatile Compound & \multicolumn{1}{l}{$\begin{array}{l}\text { Retention } \\
\text { Time }\end{array}$} & \multicolumn{2}{c}{ Musammi } & \multicolumn{2}{l|}{$\begin{array}{l}\text { Red Blood } \\
\text { Orange }\end{array}$} & Kinnow \\
\hline Ethyl acetate & 1.152 & 0.89 & 0.15 & 0.15 \\
\hline Camphene & 1.463 & 0.32 & ---- & 0.18 \\
\hline Acetaldehyde & 1.620 & 3.56 & 3.56 & 3.56 \\
\hline Geraniol & 1.960 & 10.02 & 24.0 & 12.67 \\
\hline Limonine & 2.823 & 48.9 & 46.30 & 54.57 \\
\hline Myrcene & 3.780 & 4.67 & ---- & 2.89 \\
\hline$\gamma$-undecalactone & 3.948 & 5.00 & ---- & ---- \\
\hline Citraniol & 5.545 & 10.05 & 10.40 & 14.00 \\
\hline Eugenol & 6.013 & 7.5 & 12.90 & 8.90 \\
\hline Others (Unidentified) & & 1.48 & 2.70 & 3.08 \\
\hline
\end{tabular}

The data are mean \pm S.D. of peel essential oil from three different samples of each Citrus cultivar analysed in triplicate

\section{Antimicrobial activities}

The results related to antibacterial activity of peel essential oils from different Citrus cultivars against two Gram +ve bacteria such as S. aureus (Staphylococcus aureus, API Staph TAC 6736152) and Bacillus subtilis (B. subtilis JS 2004) and two Gramve bacteria: E. coli (Escherichia coli ATCC 25922), and P. multocida (Pasteurella multocida, local isolate) are presented in (Table 3$)$. In the present study Kinnow ( $C$. reticulata) peel essential oil revealed maximum zone of inhibitions against microbial strains i.e. B. subtilis, $(26.16 \mathrm{~mm})$ S. aureus $(25.50 \mathrm{~mm})$, E.coli $(37.42 \mathrm{~mm})$ and P.multocida $(35.50 \mathrm{~mm})$ as compared to peel essential oil of Musammi (C. sinensis) 17.33,15.42,30.33, $21.00 \mathrm{~mm}$ and Red blood orange (C. $\times$ sinensis) $25.55,23.0,31.83,30.58 \mathrm{~mm}$, respectively. These values revealed that $C$. reticulata peel essential oil is more active against all the bacterial strains as compared to essential oils of C.sinensis and C. $x$ sinensis [34].

Table 3. Antibacterial activity of peel essential oils from different Citrus cultivars

\begin{tabular}{|c|c|c|c|c|}
\hline \multirow{3}{*}{ Cultivar } & \multicolumn{4}{|c|}{ Inhibition zone diameters (mm) } \\
\hline & \multicolumn{2}{|c|}{ Gram-positive bacteria } & \multicolumn{2}{|c|}{ Gram-negative bacteria } \\
\hline & B. subtilis & S. aureous & E. coli & P. multocida \\
\hline Citrus reticulata & $26.16 \pm 0.28^{\mathrm{a}} \mathrm{A}$ & $25.50 \pm 0.50^{\mathrm{a}} \mathrm{A}$ & $37.42 \pm 0.38^{\mathrm{a}} \mathrm{B}$ & $35.50 \pm 0.50^{\mathrm{a}} \mathrm{C}$ \\
\hline Citrus sinensis & $17.33 \pm 0.58^{\mathrm{b}} \mathrm{A}$ & $15.42 \pm 0.58^{\mathrm{b}}{ }_{\mathrm{B}}$ & $30.33 \pm 0.58^{\mathrm{b}}{ }_{\mathrm{C}}$ & $21.00 \pm 1.00^{\mathrm{b}}{ }_{\mathrm{D}}$ \\
\hline Citrus $x$ sinensis & $25.55 \pm 1.00^{\mathrm{c}} \mathrm{A}$ & $23 \pm 1.00^{\mathrm{c}}{ }_{\mathrm{B}}$ & $31.83 \pm 1.04^{\mathrm{b}} \mathrm{C}$ & $30.58 \pm 0.52^{\mathrm{c}} \mathrm{C}$ \\
\hline $\begin{array}{l}\text { Standard drug } \\
\text { (Amoxycillin) }\end{array}$ & $43.00 \pm 1.00^{\mathrm{d}} \mathrm{A}$ & $38.41 \pm 0.38^{\mathrm{d}}{ }_{B}$ & $42.50 \pm 1.32^{\mathrm{d}} \mathrm{A}$ & $43.00 \pm 1.00^{\mathrm{d}} \mathrm{A}$ \\
\hline
\end{tabular}

Values expressed as means \pm SD of three separate experiments performed $(n=3 \times 3)$. Different caps letters in subscript within the same row express significant $(p<0.05)$ variations of means among bacterial strains. Difference of superscript letters within the same column express significant $(p<0.05)$ differences of means among the Citrus cultivars 
The considerable antibacterial activity of peel essential oil (EO) of Kinnow ( $C$. reticulata) is in line with the results of Sultana et al. [35], and Javaid et al. [36], who reported that among Citrus cultivars tested, Citrus reticulata was highly effective against all microbial strains. Peel EO's of Citrus species exhibited appreciable equal antibacterial activity on both gram +ve and gram -ve bacteria [37, 38]. The variable antibacterial activity of Citrus EOs can be mainly attributed to the variation in the composition of constituents such as oxygenated monoterpenes and phenolics in due part to their genetic makeup. $[39,41]$.

\section{Antifungal activity}

The results of antifungal activity of the tested Citrus peel essential oils against $C$. albican (Candida albicans), M. canis (Microsporum canis), A. flavus (Aspergillus flavus) and F.solani (Fusarium solani) are shown in (Table 4). Peel EO of Red blood orange (Citrus $x$ sinensis) presented maximum zone of inhibitions against $A$. flavus $(29.0 \mathrm{~mm})$ and F.solani $(32.0 \mathrm{~mm})$. But in case of M.canis $(23.30 \mathrm{~mm})$ and C.albicans $(22.50 \mathrm{~mm})$ it gave less zone of inhibitions than Kinnow (C. reticulata) A.flavus $(26.00 \mathrm{~mm})$, F.solani $(31.0 \mathrm{~mm})$, M.canis $(24.17 \mathrm{~mm})$, C.albicans $(22.83 \mathrm{~mm})$.

Table 4. Antifungal activity of peel eessential oils from different Citrus cultivars

\begin{tabular}{|c|c|c|c|c|}
\hline \multirow{2}{*}{ Cultivar } & \multicolumn{4}{|c|}{ Inhibition zone diamtere (mm) } \\
\hline & C. albican & M. canis & A. flavus & F.solani \\
\hline Citrus reticulate & $22.83 \pm 0.76^{\mathrm{a}} \mathrm{A}$ & $24.17 \pm 0.29^{a}{ }_{B}$ & $26.00 \pm 1.00^{\mathrm{a}} \mathrm{C}$ & $31.00 \pm 1.00^{\mathrm{a}} \mathrm{D}$ \\
\hline Citrus sinensis & $13.67 \pm 0.58^{\mathrm{b}} \mathrm{A}$ & $17.5 \pm 0.50^{\mathrm{b}}{ }_{\mathrm{B}}$ & $25.67 \pm 0.58^{\mathrm{b}} \mathrm{C}$ & $23.50 \pm 0.50^{b}{ }_{D}$ \\
\hline Citrus $x$ sinensis & $22.50 \pm 0.50^{\mathrm{A}}{ }_{\mathrm{A}}$ & $23.30 \pm 0.26^{\mathrm{a}} \mathrm{B}$ & $29 \pm 1.00^{\mathrm{c}} \mathrm{C}$ & $32.00 \pm 1.00^{\mathrm{c}} \mathrm{D}$ \\
\hline Flumequine & $37.33 \pm 1.1_{\mathrm{A}}^{\mathrm{c}}$ & $38.00 \pm 1.00^{\mathrm{c}}{ }_{\mathrm{B}}$ & $39.00 \pm 0.50^{\mathrm{d}} \mathrm{C}$ & $42.00 \pm 1.00^{\mathrm{d}} \mathrm{D}$ \\
\hline
\end{tabular}

Values expressed as means \pm SD of three separate experiments $(n=3 \times 3)$. Various caps letters in subscript within the same row express significant $(p<0.05)$ differences of means among different fungal strains. Difference superscript letters within the same column express significant $(p<0.05)$ differences of means among Citrus species

These values of inhibition zones revealed that peel EO of Red blood orange (C. $x$ sinensis) is more active against $A$.flavus and F.solani while that of Kinnow (C.reticulata) is more potent against C.albicans and M.canis. Meanwhile, Musammi (C. sinensis) peel EO exhibited weaker activity against A.flavus (25.67 $\mathrm{mm})$, F.solani $(23.50 \mathrm{~mm})$, M.canis $(17.50$ $\mathrm{mm})$, C.albicans $(13.67 \mathrm{~mm})$ than peel EO of Red blood orange (C. $x$ sinensis) and Kinnow (C. reticulata). Citrus essential oils possess considerable anti-fungal activities. The presence of chemical compounds such as $\alpha$-pinene, linalool and $\alpha$-terpineol can be linked to antifungal potential of the oils [42]. Citral is one of the main components of essential oils that acts as a fungicidal since it is capable of forming a charge transfer complex with fungal cells [43].

Furthermore, the variable susceptibilities of the tested organisms to citrus peel essential oils might be ascribed to the variations in the rate of essential oil constituent's penetration via the cell wall and cell membrane components of organisms [4446]. This indicates that antimicrobial activity of the tested Citrus EO's are not only cultivars dependent nevertheless this potential is also dependant on the genetic make of the microbial strains [47].

\section{Cytotoxic/haemolytic activity}

Essential oils from peels of different Citrus cultivars exhibited negligible cytotoxicity $(0.29-1.09 \%)$ as compared to positive control, Triton X-100 which offered $100 \%$ haemolytic activity

as expressed in (Table 5). 
Table 5. Cytotoxic activity of peel essential oils from different Citrus cultivars

\begin{tabular}{|l|l|}
\hline Cultivar & Cytotoxic/Haemolytic Activity (\%) \\
\hline Citrus reticulate & $0.29 \pm 0.02$ \\
\hline Citrus sinensis & $1.09 \pm 0.34$ \\
\hline Citrus $x$ sinensis & $0.62 \pm 0.12$ \\
\hline PBS & 0.00 \\
\hline Triton-X-100 & 100 \\
\hline
\end{tabular}

Obtained results clearly depicted that Citrus peel essential oils have very low cytotoxic activity and can be safe to use for nutrapharmaceutical applications [48]. This cytotoxic is interesting property of many saponins to bring about haemolysis i.e. the release of haemoglobin from erythrocytes as result of change in membrane permeability [49].

Some other plants have also been studied for the haemolytic activity towards humans or animal erythrocytes [50]. Although the cytotoxicity of essential oils of Citrus reticulata and Citrus sinensis have been checked against pests, but no data is available on their haemolytic activities against human red blood cells.

\section{Conclusion}

Among the Citrus cultivars selected, Musammi (C. sinensis) peels exhibited greater yield of essential oil as compared to Kinnow and then Red blood orange peels. Limonene was found as a major component in three Citrus cultivars. All Citrus peel oils revealed variable volatile composition owing to differences in genetic makeup of the cultivars. The tested Citrus peel essential oils exhibited appreciable antibacterial, antifungal activities. Kinnow (Citrus reticulata) peel essential oil exhibited maximum antibacterial and antifungal activity, while other Citrus peel oils revealed relatively lesser biological activities. The tested essential oils also gave negligible level of cytotoxicity and thus can be safe to use as valuable ingredients in nutra-

pharmaceutical products. Moreover, it can be depicted that hydrodistillation is an appropriate choice for isolation of essential oils from under-utilized Citrus peels. The hydrodistilled Citrus peel essential oils can be utilized as natural antioxidant and antimicrobial agents leading to valueaddition in Citrus fruit processing industry. Authors' contributions

Conceived and designed the experiments: $\mathrm{F}$ Anwar \& $\mathrm{T}$ Mehmood, Performed the experiments: R Qadir, S Zahoor \& $M$ Shahid, Analyzed the data: F Anwar, T Mehmood \& M Shahid, Contributed reagents/ materials/ analysis tools: F Anwar \& T Mehmood, Wrote the paper: F Anwar \& R Qadir.

\section{References}

1. Ahmadi L, Mirza M, \& Shahmir F (2002). The volatile constituents of Artemisia marschaliana Sprengel and its secretory elements. Flav Fragr J 17: 141-143.

2. Bezic N, Samanic I, Dunkic V, Besendorfer V \& Puizina J (2009). Essential oil composition and internal transcribed spacer (ITS) sequence variability of four South-Croatian Satureja species (Lamiaceae). Molecules 14: 925-938.

3. Kamaliroosta L, Zolfaghari M, Shafiee S, Larijani K \& Zojaji M (2016). Chemical identifications of Citrus peels essential oils. J Food Bio Tech 6 (2): 6976.

4. Hussain AI, Anwar F, Sherazi STH \& Przybylski R (2008). Chemical composition, antioxidant and antimicrobial activities of basil (Ocimum basilicum) essential oils depend on seasonal variations. Food Chem 108: 986-995.

5. Hussain AI, Anwar F, Chathta SAS , Latif S, Sherazi STH , Ahmad A, Worthington J \& Sarker SD (2013). Chemical composition and bioactive studies of the essential oils from two 
Thymus species from the Pakistani flora. LWT: Food Sci Tech 50: 185192.

6. Kamal GM, Anwar F, Hussain AI, Sarri N \& Ashraf MY (2011). Yield and chemical composition of Citrus essential oils as affected by drying pretreatment of peels. Int Food Res J 18(4): 1275-1282.

7. Chutia M, Bhuyan P D, Pathak M G, Sarma TC \& Boruah P (2009). Antifungal activity and chemical composition of Citrus reticulata Blanco essential oil against phytopathogens from North East India. LWT: Food Sci Tech 42: 777-780.

8. Ahmad MM, Rehman S, Iqbal Z, Anjum FM, \& Sultan JI (2006). Genetic variability to essential oil composition in four Citrus fruit species. Pak J Bot 38: 319-324.

9. Javed S, Ahmad R, Shahzad K, Nawaz S, Saeed S \& Saleem Y (2013). Chemical constituents, antimicrobial and antioxidant activity of essential oil of Citrus limetta var. Mitha (sweet lime) peel in Pakistan. Afric J Micro Res 7(24): 3071-3077.

10. Fisher K \& Phillips C (2008). Potential antimicrobial uses of essential oils in food.Is citrus the answer. Trends in Food Sci Tech 19: 156-164.

11. Myoatasayoh JC, Kiplimo JJ, Karubiu NM \& Hailstroks TP (2007). Chemical Composition and antimicrobial activity of essential oil of Tarchanthus camphorates. Food Chem 101: 11831187.

12. Manzoor M, Anwar F, Mahmood Z, Rashid U \& Ashraf M (2012). Variation in minerals, phenolics and antioxidant activity of peel and pulp of different varieties of peach (Prunus persica L.) fruit from Pakistan. Molecules 17: 6491-6506.

13. Marina Z \& Noriham A (2014). Quantification of total phenolic compound and in vitro antioxidant potential of fruit peel extracts. Int Food Rese J 1925-1929.
14. Cholke PB, Bhor AK, Shete AM \& Sonawane RK (2017). Extraction and GC-Ms Analysis of Orange (Citrus sinensis) Peel Oil. Res J Agri Bio Sci 2(5): 41-51.

15. Carpano S, Hachey JM \& Collin GJ (1988). The variations of essential oil composition during the extraction process: the case of Thuja occidentalis L. and Abies balsamea L. J Wood Tech 8: 561-573.

16. Mehmood N, Zubair M, Rizwan K, Rasool N, Shahid M \& Ahmad VU (2012). Antioxidant, Antimicrobial and Phytochemical analysis of Cichorium intybus seeds extract and various organic fractions. Iran J Pharm Res 11(4): 1145-1151.

17. Tabasum S, Zuber M, Jami LTR, Shahid M \& Hussain R (2013). Antimicrobial and pilling evaluation of the modified cellulosic fabrics using polyurethane acrylate copolymers. Int J Bio Macromol 56: 99-105.

18. Riaz M, Rasool N, Bukhari IH, Shahid M, Zubair M, Rizwan K \& Rashid U (2012). Chemical composition, in vitro antimicrobial, antioxidant and cytotoxicity studies of Mazus goodenifolius. Molecules 17: 1427514287.

19. Anwer J, Ali S, Shahzadi S, Shahid M, Saroj KS \& Qanungo K (2013). Synthesis, characterization, semiempirical study and biological activities of homo bimetallic complexes of tranexamic acid with organotin (IV). J Coord Chem 66(7): 1142-1152.

20. Weiss EA (1997). Essential Oil Crops. CAB Intl N Y USA 417-515.

21. Manthey JA \& Grohmann K (2001). Phenolics in citrus peel by-products concentrations of hydroxycinnamates and polymethoxylated flavones in citrus peel molasses. J Agri Food Chem 49: 3268-73

22. Huet R (1991). Les huilles essentials d'agrumes. Fruits 46: 551-76. 
23. Tu MNT, Onishi Y, Choi HS, Kondo Y, Bassore SM, Ukeda H \& Sawamura M. (2002). Characteristic odor components of Citrus sphaerocarpa Tanaka (Kabosu) cold pressed peel oil. J Agri Food Chem 50: 2908-2913.

24. Anonymous (2004). Oil of Lemon Oleum aurantii.British Pharmaceutical Codex.http://www.biblio.Org/herbmd/ eclectic/bpc1911/citrus_limon_.html.

25. Ahmad MM, Rehman S, Iqbal Z, Anjum FM \& Sultan JI (2006). Genetic variability to essential oil composition in four citrus fruit species. Pak J Bot 38: 319-324.

26. Kamal GM, Anwar F, Hussain AI, Sarri N \& Ashraf MY (2011). Yield and chemical composition of Citrus essential oils as affected by drying pretreatment of peels. Int Food Res $J$ 18(4): 1275-1282.

27. Geraci A, Stefano VD, Martino ED, Schillaci D \& Schicchi R (2017). Essential oil components of orange peels and antimicrobial activity. J Agri Food Chem, 31(6): 653-659.

28. Lota Ml, Serra DR, Tomi F \& Casanova J (2001). Chemical variability of peel and leaf essential oils of 15 species of mandarins. Biochem System Eco 29(1): 77-104.

29. Feger W, Brandauer $\mathrm{H}$ \& Ziegler $\mathrm{H}$ (2003). Analytical investigation of Murcott (Honey) tangerine peels oil. $J$ Essen Oil Res 15(3): 143-147.

30. Carpano SM, Spegazzini ED, Rossi JS, Castro MT \& Debenedetti Sl (2003). Antifungal activity of Terminalia australia. Fitoterapia, 74: 294-297.

31. Haristoy X, Angioi-duprez K, Duprez A \& Lozniewski A (2003). Efficacy of sulforaphane in eradicating Helicobacter pylori in human gastric xenografts implanted in nude mice. Anti Agents Chemo 47: 3982-3984.

32. Hassiotis C, Lazari D \& Vlachonasios K (2010). The effects of habitat type and diurnal harvest on essential oil yield and composition of Lavandula
Aagustifoli Mill. Fresen Envir Bulletin 19: 1491-1498.

33. Sangwan N, Farooqi A, Shabih F \& Sangwan R (2001). Regulation of essential oil production in plants. $J$ Plant Growth Regu 34: 3-21.

34. Hamdan DI, Abdullah RH, Mohamed ME \& El-shazly AM (2013). Chemical composition and biological activity of essential oils of Cleopatra mandarin (Citrus reshni) cultivated in Egypt. $J$ Pharm and Phyto 5(5): 83-90.

35. Sultana HS, Ali M \& Panda BP (2012). Influence of volatile constituents of fruit peels of Citrus reticulata Blanco on clinically isolated pathogenic microorganisms under In-vitro. Asian Pac J Trop Bio 1299-1302.

36. Javed S, Javaid A, Mahmood Z, Javaid A \& Nasim F (2011). Biocidal activity of citrus peel essential oils against some food spoilage bacteria. $\mathrm{J}$ Med Plants Res 5(16): 3697-3701.

37. Shahzad K, Nawaz S, Ahmad R, Mahmud S, Iqbal Z \& Saeed K (2009). Evaluation of antioxidant and antimicrobial activity of essential oil of Tangerine fruit peel. Pak J Biochem Mole Bio. 42, 4-7.

38. Ravi KU, Dwivedi P \& Ahmad S (2010). Screening of antibacterial activity of six plants essential oils against pathogenic bacterial strains. Asian J Med Sci 2: 152-158.

39. Sokovic M, Grubisic D \& Ristic M (2005). Chemical composition and antifungal activity of the essential oils from leaves, calyx and corolla of Salvia brachyodon Vandas. J Essen Oil Res 17: 227-229.

40. Sokovic M \& Van GL (2006). Antimicrobial activity of essential oils and their components against the three major pathogens of the cultivated button mushroom, Agaricus bisporus. European J Plant Path 116: 211-224.

41. Gardini F, Belletti N, Ndagijimana M, Guerzoni ME, Tchoumbougnang $\mathrm{F}$, Zollo PHA, Micci C, Lanciotti R, Sylvain L \& Kamdem S (2009). 
Composition of four essential oils obtained from plants from Cameroon, and their bactericidal and bacteriostatic activity against Listeria monocytogenes, Salmonella enteritidis and Staphylococcus aureus. Afri J Micro Res 3(5): 264-271.

42. Johann S, Oliveira VL, Pizzolatti MG, Schripsema J, Braz-Filho R, Branco A \& Smania A (2007). Antimicrobial activity of wax and hexane extracts from Citrus spp.peels. Mem Do Inst Oswaldo Cruz 102: 0074-0276.

43. Sokovic M, Marin PD, Brkic D \& Griensven LJLDV (2007). Chemical composition and antibacterial activity of essential oils of ten aromatic plants against human pathogenic bacteria. Food 1 X-Y.

44. Palakawong C, Sophanodora P, Pisuchpen S \& Phongpaichit S (2010). Antioxidant and antimicrobial activities of crude extracts from mangosteen (Garcinia mangostana L.) parts and some essential oils. Int Food Res J 17: 583-589.

45. Pandey RR, Dubey RC \& Saini S (2010). Phytochemical and antimicrobial studies on essential oils of some aromatic plants. Afri J Biotech 9: 4364-4368.

46. Keleş OSA, Bakirel $\mathrm{T}$ \& Alpinar $\mathrm{K}$ (2001). Screening of some Turkish plants for antibacterial activity. Turk $J$ Vet Anim Sci 5(4): 559-565.

47. Kurita N, Miyaji M, Kurane R \& Takahara Y (1981). Antifungal activity of components of essential oils. Agri Bio Chem 45: 945-952.

48. Rizwan K, Zubair M, Rasool N, Riaz M, Zia-Ul-Haq M \& Feo V (2012). Int $J$ Mole Sci 13:6440.

49. Hook F, Inalegwu B \& Sodipo OA (2013). Phytochemical screening and haemolytic activities of crude and purified saponins of aqueous and methanolic extracts of leaves of Tephrosia vogelii. Asian Int J Plant Sci Res 3(5):7-11.

50. Mathur PR, Mathur D, Prasad GBKS \& Dua VK (2011). Pharmacological investigation of methanol extract of Syzigum cuminii seeds and Crateva nurvula bark on the basis of antimicrobial, antioxidant and antiinflammatory properties. Der Chemica Sinica 2(1): 174-181. 